Published in final edited form as:

PET Clin. 2018 July ; 13(3): 339-354. doi:10.1016/j.cpet.2018.02.006.

\title{
Overview of Breast Cancer Therapy
}

Tracy-Ann Moo, MD¹, Rachel Sanford, MD² $^{2}$ Chau Dang, MD $^{3}$, and Monica Morrow, MD 4

${ }^{1}$ Breast Service, Department of Surgery, Memorial Sloan Kettering Cancer Center, New York, NY, USA, 300 East $66^{\text {th }}$ Street, New York, NY, 10065

${ }^{2}$ Breast Medicine Service, Department of Medicine, Memorial Sloan Kettering Cancer Center, New York, NY, USA, 300 East 66 $6^{\text {th }}$ Street, New York, NY, 10065

${ }^{3}$ Breast Medicine Service, Department of Medicine, Memorial Sloan Kettering Cancer Center, New York, NY, USA, 300 East $66^{\text {th }}$ Street, New York, NY, 10065

${ }^{4}$ Breast Service, Department of Surgery, Memorial Sloan Kettering Cancer Center, New York, NY, USA, 300 East $66^{\text {th }}$ Street, New York, NY, 10065

\section{Synopsis}

Breast cancer treatment is multidisciplinary. The majority of women with early-stage breast cancer are candidates for breast-conserving surgery with radiotherapy or mastectomy. The risk of local recurrence and the chance of survival does not differ with these approaches. Sentinel node biopsy is used for axillary staging, and individualized approaches are minimizing the need for axillary dissection in sentinel node-positive women. Adjuvant systemic therapy is used in the majority of women based on proven survival benefit, and molecular profiling to individualize treatment based on risk is now a clinical reality for patients with hormone receptor-positive cancers. Follow-up surveillance consists of a history, physical examination, and annual mammography. Following adjuvant systemic treatment, there is currently no evidence that routine imaging improves outcomes in the absence of symptoms. Novel modalities for early tumor detection are welcomed, but will need to demonstrate clinical utility in prospective trials.

\section{Keywords}

breast cancer therapy; local therapy; adjuvant therapy breast-conserving therapy; mastectomy; neoadjuvant chemotherapy; breast cancer surveillance; endocrine therapy

The diagnosis and treatment of invasive breast cancer requires a collaborative effort among multiple subspecialties. Diagnostic imaging work-up and biopsy play a key role in establishing a diagnosis, and informing surgical decisions on management of the primary

Corresponding Author: Monica Morrow, MD, Breast Service, Department of Surgery, Memorial Sloan Kettering Cancer Center, 300 East 66 ${ }^{\text {th }}$ Street, New York, NY, 10065, (T) 646888 5350, (F) 535888 5365, (E) morrowm@ @ mskcc.org.

Publisher's Disclaimer: This is a PDF file of an unedited manuscript that has been accepted for publication. As a service to our customers we are providing this early version of the manuscript. The manuscript will undergo copyediting, typesetting, and review of the resulting proof before it is published in its final citable form. Please note that during the production process errors may be discovered which could affect the content, and all legal disclaimers that apply to the journal pertain. 
tumor, staging of the axilla, and the sequence of therapy. Once a diagnosis of breast cancer is established, the extent of disease is assessed which, for the most part, determines whether or not preoperative (neoadjuvant) systemic therapy is indicated. Confirmed stage IV breast cancer is considered incurable; it is treated with systemic therapy alone unless there is an indication for palliative resection of the primary tumor and will not be discussed further. An important part of the initial clinical evaluation of the patient with non-metastatic breast cancer is to identify clinical criteria of inoperability which necessitate the use of neoadjuvant therapy. These include inflammatory carcinoma, fixation of the tumor to the bony chest wall (ribs, sternum), extensive skin involvement with ulceration or satellite skin nodules, fixed/ matted axillary lymphadenopathy, involvement of neurovascular structures of the axilla, or lymphedema of the ipsilateral arm. All of these findings are readily identifiable on physical examination and should prompt an imaging evaluation for distant metastases. In these cases, systemic therapy is administered as initial treatment to reduce tumor volume and will render approximately $80 \%$ of patients operable. ${ }^{1}$ In those patients who present with operable disease, the sequence of surgical resection and systemic therapy is variable. Preoperative systemic therapy may be used to reduce tumor volume in the breast, allowing breast conservation when mastectomy would otherwise be necessary, and to decrease the need for axillary lymph node dissection (ALND). In the majority of patients presenting with stage I and II disease, resection of the tumor is the initial step in management, and patients have the option of breast conservation or mastectomy.

\section{Local therapy for invasive breast cancer: breast-conserving therapy and mastectomy}

Breast-conserving therapy (BCT) and mastectomy are both well-established local therapies for invasive breast cancer. Multiple randomized clinical trials with follow-up of up to 20 years have demonstrated that BCT is safe and has survival outcomes equivalent to mastectomy in stage I and II breast cancer. ${ }^{2-6}$ Although a few earlier trials reported higher rates of locoregional recurrence (LRR) following BCT than were seen after mastectomy $(10-22 \%),{ }^{2,4,7}$ much lower LRR rates are reported in contemporary studies. The decrease in LRR can be attributed to the implementation of microscopic confirmation of negative resection margins and the widespread use of systemic therapy. In a study of LRR in patients with node-negative and node-positive breast cancer receiving systemic therapy after BCT in five National Surgical Adjuvant Breast and Bowel Project (NSABP) protocols, 10-year local recurrence rates were $5.2 \%$ and $8.7 \%$, respectively. ${ }^{8,9}$ These rates are comparable to observed 10-year rates of isolated local recurrence after mastectomy of approximately $8 \% .{ }^{10}$ It is now understood that local control is not solely a function of disease burden and extent of surgery, but varies with tumor molecular subtype and administration of systemic therapy. Rates of local recurrence differ significantly among breast cancer subtypes, regardless of whether patients are treated with mastectomy or BCT. Local recurrence rates are highest among patients with hormone receptor (HR) negative, HER2 negative cancers ("triple negative"), and lowest among patients with HR positive, HER2 negative cancers. ${ }^{11,12}$ This understanding eliminates the rationale for treating biologically aggressive cancers with mastectomy, and the majority of patients with stage I and II disease are candidates for BCT. 


\section{Breast-conserving therapy}

BCT involves excision of the tumor (lumpectomy) followed by adjuvant whole breast irradiation (WBI). In order to perform BCT, it must be possible to excise the tumor to negative margins with an acceptable cosmetic outcome, the patient must be able to receive radiotherapy, and the breast must be suitable for follow-up to allow prompt detection of local recurrence. The contraindications to $\mathrm{BCT}$ arise logically from these requirements.

Contraindications to BCT include the presence of diffuse suspicious or malignant appearing calcifications, disease that cannot be resected to negative margins with a satisfactory cosmetic result, and the presence of contraindications to delivery of radiation such as prior treatment of the breast field or active scleroderma. ${ }^{13} \mathrm{~A}$ negative margin is defined as "no ink on the tumor". ${ }^{13,14}$ More widely clear margins do not improve local control in invasive breast cancer and are not required for BCT. ${ }^{15}$ If negative margins can be achieved with an acceptable cosmetic outcome, then lumpectomy can be performed irrespective of tumor size. In women with large tumors relative to breast size, neoadjuvant chemotherapy (NAC) can be used to downstage the tumor (see below). Young age, aggressive tumor subtype (HER2 positive and triple negative), and lobular histology are not contraindications to BCT. In patients with BRCA1/2 mutations, bilateral mastectomy is a consideration, as the risk of a new primary breast cancer development can range from $26-40 \%$ over the 20 years following diagnosis depending upon age of onset of the initial cancer, performance of oophorectomy, and use of endocrine therapy. ${ }^{16}$ Despite this higher risk, a BRCA mutation is not an absolute contraindication to breast conservation, and patient preference must also be considered.

Physical examination, mammography, and diagnostic ultrasound are the imaging modalities in standard use to select patients for BCT. In a population-based study of 1,984 women with ductal carcinoma in situ and stage I and II invasive cancers, $88 \%$ of those attempting BCT successfully had the procedure. This is probably an underestimate of the number of women eligible for BCT since many were converted to mastectomy without an attempt at reexcision. ${ }^{17}$ The use of magnetic resonance imaging (MRI) in the preoperative setting is controversial. MRI is more sensitive than mammography or ultrasound, detecting additional disease in $16 \%$ of patients in a meta-analysis. ${ }^{18}$ It was hoped that MRI would improve selection of lumpectomy candidates and decrease rates of reoperation. However, multiple studies of preoperative MRI have demonstrated an increase in both ipsilateral mastectomy for the index tumor and contralateral prophylactic mastectomy rates without an accompanying reduction in reoperation and recurrence rates. ${ }^{19-26}$ A systematic review which included 85,975 patients examined the association between preoperative MRI and surgical outcomes. MRI was associated with an increased likelihood of undergoing ipsilateral mastectomy (odds ratio [OR] 1.39;95\% confidence interval [CI] 1.23-1.57; $\mathrm{p}<$ 0.001 ), and contralateral prophylactic mastectomy (OR 1.9; 95\% CI 1.25-2.91; $\mathrm{p}=0.003$ ) after adjusting for patient age. The use of preoperative MRI did not significantly reduce the rate of positive margins, reoperation, or re-excision. ${ }^{27}$ Additionally, an individual patientlevel meta-analysis of the impact of MRI on local recurrence rates after BCT observed no differences in patients selected with and without MRI. ${ }^{24}$ The failure of detection of subclinical disease with MRI to translate into improved local recurrence outcomes is consistent with the understanding that local recurrence is determined not only by tumor 
burden, but by tumor biology and the use of effective adjuvant systemic therapy. In the absence of a specific clinical question, routine use of preoperative MRI is not indicated. Specific instances where a preoperative MRI might be clinically useful include mammographically and/or sonographically occult tumors, Paget's disease, evaluation of extent of residual disease following NAC in patients desiring conservation, and when significant differences in the assessment of tumor size by physical examination, mammography, and ultrasound are seen.

\section{Adjuvant radiation in breast-conserving therapy}

It is important to determine preoperatively whether or not the patient is a candidate for adjuvant radiation. Prior chest wall irradiation, pregnancy at the time of diagnosis, and the presence of a connective tissue/collagen vascular disorder may be contraindications to radiation treatment. Patients with a history of mantle radiation delivered for Hodgkin's lymphoma may be ineligible for adjuvant radiation if the radiation threshold dose has been exceeded during prior therapy. Delivery of radiation is contraindicated during all trimesters of pregnancy. However, in a woman presenting with invasive breast cancer in the second or third trimester, a lumpectomy can be performed and adjuvant chemotherapy administered followed by breast irradiation in the postpartum period. In cases where breast cancer is diagnosed in the first trimester without an indication for adjuvant chemotherapy, mastectomy is the preferred procedure. Connective tissue/collagen vascular disorders including scleroderma, Sjogren's syndrome, systemic lupus erythematosus, and dermatomyositis/polymyositis are considered relative contraindications to the delivery of breast irradiation due to small retrospective studies suggesting an increased incidence of acute and late radiation toxicities in these patients. With the exception of scleroderma, matched case control studies have not consistently demonstrated an increase in risk; however, these were very small retrospective studies in which patients with severe disease were likely not selected for radiation. ${ }^{28-30}$ Preoperative consultation with a radiation oncologist is warranted in these patients.

WBI is given following lumpectomy to eliminate residual microscopic disease that may remain in the breast even when negative margins are obtained. Holland et $\mathrm{al}^{31}$, in pathologic studies of mastectomy specimens in 282 patients with clinical and mammographically unifocal breast cancers, found additional tumor foci within $2 \mathrm{~cm}$ of the index tumor in 56 (20\%) cases and $>2 \mathrm{~cm}$ from the index cancer in $121(43 \%)$ cases. The delivery of adjuvant radiation following lumpectomy decreases local failure rates by about $50 \%$ and increases breast cancer-specific survival. ${ }^{2-4,6}$ The Early Breast Cancer Trialists' Collaborative Group (EBCTCG) meta-analysis of 17 randomized trials including 10,801 women undergoing BCT demonstrated a reduction in the risk of any recurrence at 10 years from $35 \%$ to $19.3 \%$ and a 15-year absolute reduction in the risk of death from breast cancer of 3.8\% (95\% CI 1.6-6.0, $\mathrm{p}=0.00005$ ) with radiation. Investigators extrapolate that for every 4 recurrences that are prevented at 10 years, there is a corresponding avoidance of 1 breast cancer death at 15 years. ${ }^{6}$

These data specifically focused on the delivery of conventional WBI consisting of 50 Gray (Gy) in 25 fractions, daily over the course of approximately 5-7 weeks, followed by a boost 
of approximately $10 \mathrm{~Gy}$ to the tumor bed. Hypofractionated WBI reduces the number of treatments needed by delivering a larger fraction over a shorter period of time and allowing completion of treatment in approximately 3 weeks. Equivalent local recurrence rates at 5 and 10 years, no difference in overall survival, and improved cosmetic outcomes compared to conventional fractionation were observed in randomized trials. ${ }^{32-34}$ Partial breast irradiation (PBI) involves radiation of a limited volume of breast tissue centered around the tumor cavity. PBI can be delivered using various techniques, including interstitial or intracavitary brachytherapy, intraoperative radiotherapy, or traditional external beam treatment. Potential advantages of PBI include shorter treatment time and irradiation of only a portion of the breast, possibly allowing repeat BCT should a new primary tumor develop. There are on ongoing trials aimed at determining whether or not PBI is as effective as conventional or hypofractionated WBI in terms of local control, survival, and cosmesis.

A subgroup of BCT patients not benefitting from radiotherapy has not been identified using conventional tumor pathologic features. However, two prospective randomized trials demonstrated acceptable local control rates without radiation in older postmenopausal women, with small estrogen receptor positive tumors receiving adjuvant endocrine therapy. 35,36 Women 70 years of age and older with estrogen receptor positive stage I breast cancer who will receive endocrine therapy are considered candidates for this approach.

A number of studies have shown an improvement in quality of life outcomes following BCT, greater cosmetic satisfaction with BCT compared to mastectomy without reconstruction, and equivalent satisfaction compared to mastectomy with immediate reconstruction. ${ }^{37-40}$ The most important factor affecting cosmetic outcome after BCT is the volume of tissue removed, with a higher likelihood of a cosmetically significant defect when $>20 \%$ of the breast volume is excised. ${ }^{41}$ Given that current guidelines do not require margins wider than "no tumor on ink", a minority of patients require such large resections. In these instances, an oncoplastic procedure may be used to improve cosmetic outcomes. Oncoplastic procedures use plastic surgery tissue rearrangement and mastopexy techniques to fill in the lumpectomy defect, improving the contour of the conserved breast. The parenchymal rearrangement often results in displacement of the tumor bed and can be problematic for radiation planning.

Placement of surgical clips to mark the boundaries of the lumpectomy cavity prior to tissue rearrangement is usually done to ensure accurate cavity localization during radiation therapy. Small retrospective series of patients undergoing large resections report greater patient satisfaction with cosmesis, and similar complication and recurrence rates as conventional BCT, with the exception of fat necrosis, which is higher in oncoplastic procedures (10 vs. $25 \%)^{42,43}$

\section{Mastectomy}

In patients undergoing mastectomy, total mastectomy (simple mastectomy), skin-sparing mastectomy, and nipple areolar-sparing mastectomy are options for the majority of patients. Total mastectomy removes the breast parenchyma, nipple areolar complex, and excess skin from the chest wall, leaving only enough skin to close the incision. It is generally used when the patient will not undergo immediate reconstruction. The skin-sparing mastectomy was developed to facilitate immediate reconstruction, and removes the breast parenchyma and 
nipple areolar complex, leaving the skin as a natural envelope for placement of the tissue expander/implant or autologous flap. Multiple studies have confirmed the oncologic safety of the skin-sparing mastectomy, with local recurrence rates of approximately $6 \%$, comparable to those observed for the traditional simple mastectomy. ${ }^{44-47}$ The nipple areolar-sparing mastectomy preserves the nipple areolar complex in addition to the skin envelope and was initially used mainly in the prophylactic setting, and is now increasingly used in patients with invasive carcinoma. Local recurrence rates of 2-5\% are reported, with median follow-up ranging from 2-5 years. ${ }^{48-51}$ Most of these data represent singleinstitution retrospective series with limited follow-up, and until long-term oncologic safety has been established, patients should be carefully selected for this procedure. Although eligibility criteria vary by institution, we suggest limiting this procedure to patients with tumors $<3 \mathrm{~cm}$ and at a distance of at least $1 \mathrm{~cm}$ from the nipple which do not have extensive calcifications suggesting an extensive intraductal component.

\section{Postmastectomy radiation}

Postmastectomy radiation (PMRT) is a well-established component of breast cancer treatment in patients with advanced disease. The role of PMRT in patients with early disease, as well as those undergoing NAC, remains in evolution. The most important predictor of LRR after mastectomy is the extent of axillary nodal disease. Patients with 4 or more positive axillary lymph nodes have a $25 \%$ or greater risk of developing an LRR. ${ }^{52,53}$ Tumor size $\geq 5 \mathrm{~cm}$ is also associated with an increased risk of chest wall recurrence of > $20 \% .52,53$ For this reason, PMRT has been considered standard in these patients for many years. ${ }^{13,54}$ PMRT in women with 1-3 positive lymph nodes and T1-2 breast cancers is an area of ongoing debate. A meta-analysis by the EBCTCG demonstrated a decreased risk of local recurrence and mortality after PMRT in women with 1-3 positive lymph nodes. However, the studies included in this meta-analysis antedated the availability of modern systemic therapies, and rates of LRR in the control arms (20\%) were substantially higher than expected based on more contemporary studies. ${ }^{55-57}$ In a study at Memorial Sloan Kettering Cancer Center examining outcomes in 1331 women with T1-2 tumors and 1-3 positive axillary lymph nodes treated with mastectomy between 1995 and 2006 where radiation was selectively administered, 15\% had PMRT. At 5 years the LRR rate was 3.2\% in the PMRT group versus $4.3 \%$ in the group not receiving radiation $(\mathrm{p}=0.57)$. Age less than 50 years and lymphovascular invasion were identified as risk factors for recurrence. ${ }^{55}$ These data suggest that the decision to administer PMRT in this group should be approached in a multidisciplinary setting. Factors determining the risk of recurrence in a particular patient such as age, life expectancy, comorbidity, pathologic findings in the breast and axilla associated with a low disease burden, and biologic characteristics of the tumor associated with greater effectiveness of systemic therapy should be considered. ${ }^{58}$

As the use of NAC in operable breast cancer has increased, there is uncertainty as to whether the pre-NAC stage, post-NAC stage, or a combination of the two should be used to determine the need for PMRT. In general, PMRT is recommended following NAC in patients who present with clinical T3-4 tumors, N2-3 nodal involvement, or who have persistent nodal disease following NAC. ${ }^{59}$ The benefit of PMRT in clinical T1-2, N1 patients who have a pathologic complete response is an area of ongoing study. 


\section{Staging and management of the axilla}

The axillary nodes are the initial site of metastases in the majority of breast cancer patients, and approximately $25 \%$ of those with a normal physical exam will have nodal metastases. ${ }^{6}$ The mainstay of axillary staging for almost two decades has been the sentinel lymph node biopsy. With the exception of older patients and those with severe comorbid conditions where information on nodal status will not change therapy, all newly diagnosed invasive breast cancer patients who present with a clinically negative axilla should undergo axillary staging by sentinel lymph node biopsy. A sentinel node can be identified in $97-99 \%$ of patients using blue dye, radioactive tracers or a combination of the two. ${ }^{61-64}$ The sentinel node predicts the status of the remaining axillary nodes in $>95 \%$ of cases in the hands of experienced surgeons, and the risk of an isolated axillary recurrence after a negative sentinel node biopsy is $<1 \%$. ${ }^{65,66}$ For more than a decade, completion ALND was routinely performed for any positive axillary nodes found on sentinel node biopsy, even though approximately $50-70 \%$ of patients with positive sentinel nodes had no additional positive nodes on completion ALND. ${ }^{67-69}$ The American College of Surgeons Oncology Group (ACOSOG) Z0011 trial randomized patients with T1-2 N0 invasive breast cancer with 1 or 2 positive sentinel lymph nodes to ALND versus no further axillary surgery. ${ }^{70}$ At a median follow-up of 9.25 years, there were no differences in local recurrence, nodal recurrences ${ }^{71}$ or overall survival between the two groups. ${ }^{72}$ With the implementation of the Z0011 results into clinical practice, approximately $85 \%$ of patients who would have previously undergone a completion ALND based on positive sentinel lymph nodes are now spared this procedure.

${ }^{73}$ Completion ALND is indicated in patients with 3 or more positive sentinel lymph nodes and those found to have matted nodes intraoperatively. Importantly, Z0011 is not applicable to patients undergoing mastectomy, those receiving neoadjuvant therapy, and those treated with PBI. A completion ALND following a positive sentinel lymph node biopsy remains the standard of care for these patients. The AMAROS (After Mapping of the Axilla:

Radiotherapy or Surgery) trial enrolled a similar patient population to ACOSOG Z0011, but randomized those with 1-2 positive sentinel nodes to ALND or no further surgery with radiation of the axillary and medial supraclavicular fields. This study reported no differences in regional recurrence or survival between groups at a follow-up of 5 years, and a lower risk of lymphedema in the radiotherapy group. ${ }^{74}$ Because AMAROS also included patients undergoing mastectomy, if the finding of metastases in 1-2 sentinel nodes is sufficient indication for PMRT, axillary dissection can be avoided. However, AMAROS does not indicate that all node-positive patients require axillary radiation since the results of ACOSOG Z0011, in the absence of nodal radiation, are comparable. At present, patients felt to be at higher risk for LRR based on number of involved sentinel nodes, primary tumor size, presence of lymphovascular invasion, microscopic extracapsular tumor extension in the nodes, and young age are selected for nodal radiation therapy. ${ }^{75}$

It is often assumed that preoperative imaging is useful in selecting patients undergoing BCT who require axillary dissection. However, the clinical question has shifted from the identification of any nodal metastases to identification of patients with 3 or more nodal metastases who are not candidates for sentinel node biopsy alone, and current imaging modalities (mammogram, ultrasound, and MRI) do not reliably make this distinction. 
Pilewskie at al examined the utility of preoperative imaging in predicting the need for additional axillary surgery in 425 patients with clinical T1-2 N0 tumors and 1 or 2 positive sentinel nodes. Among patients with abnormal axillary nodes identified by mammogram, axillary ultrasound, or MRI, 71\% did not require ALND using Z0011 criteria. ${ }^{76}$ Even among patients with a needle biopsy demonstrating nodal metastases, only $45 \%$ required ALND. ${ }^{77}$ Thus, preoperative axillary imaging in clinically node-negative patients should be reserved for those undergoing mastectomy where the finding of any nodal disease is an indication for ALND or preoperative chemotherapy to downstage the axilla.

\section{Neoadjuvant chemotherapy}

NAC was initially utilized as a way of rendering locally advanced, inoperable breast cancer resectable. More recently, NAC has been used in operable tumors to downstage disease in the breast and axilla with the intention of facilitating breast conservation and, in some instances, avoiding ALND. The oncologic safety and equivalent survival outcomes of NAC have been studied in several randomized trials. ${ }^{78-80} \mathrm{~A}$ meta-analysis of patients treated with NAC versus surgery followed by chemotherapy has shown no differences in survival or LRR with NAC and a $17 \%$ decrease in the mastectomy rate in patients receiving NAC. ${ }^{81}$ Seventeen percent is a minimal estimate since many of the women enrolled in these studies were candidates for BCT at presentation and thus could not benefit from NAC. NAC is most likely to allow BCT in the woman with a unicentric cancer which is large relative to the size of her breast and in those with HER2 positive or triple negative breast cancers.

Accurate evaluation of response to therapy and the feasibility of BCT can be problematic. MRI is more accurate than mammography or ultrasound in predicting the extent of residual disease, but a normal MRI does not exclude the presence of scattered foci of viable carcinoma which may preclude BCT. ${ }^{82}$ Mammography is complimentary to MRI in evaluating suitability for BCT post-NAC as calcifications present at diagnosis infrequently resolve with NAC. Calcifications may also become apparent after neoadjuvant therapy when breast densities related to the tumor have resolved or secondary to tumor cell death. Loss of enhancement on MRI does not reliably indicate that calcifications are benign or due to dead cancer cells, ${ }^{83}$ and excision of any residual palpable masses or radiographic abnormalities is standard. Of note, the entire volume originally occupied by the tumor does not need to be removed in the lumpectomy specimen and a pathologic complete response is not a requirement for successful BCT post-NAC. Lumpectomy should include any residual clinical or imaging abnormalities, or, in the case of a clinical and radiographic complete response, removal of the marker at the tumor site and a generous sample of surrounding breast tissue.

Administration of NAC significantly reduces the rate of axillary metastases in clinically node-negative women, ${ }^{80}$ and performance of sentinel lymph node biopsy after NAC is standard in this population. ${ }^{84-87}$ More effective systemic regimens have led to increased rates of pathologic complete response in both the breast and axilla after NAC. Three prospective randomized clinical trials have examined the accuracy of sentinel node biopsy after NAC in patients presenting with nodal metastases (Table 1). The ACOSOG Z1071 and SENTINA studies suggest that with the use of dual-tracer mapping and identification of 3 or 
more negative sentinel nodes, false-negative rates are $<10 \%$, similar to what is accepted for sentinel node biopsy in the primary surgical setting. In a prospective study from Memorial Sloan Kettering Cancer Center, $48 \%$ of 288 patients who presented with nodal metastases and became clinically node negative after NAC had a nodal pathologic complete response and 3 or more identifiable sentinel nodes, and were able to avoid axillary dissection. ${ }^{88} \mathrm{In}$ patients who remain node positive, completion ALND is standard. The question of whether or not axillary radiation can be substituted for a completion ALND in the setting of a positive axillary sentinel node after NAC is currently being addressed in the Alliance A011202 trial.

\section{Adjuvant medical therapies for breast cancer}

Following surgical resection of the primary breast cancer, patients often receive adjuvant systemic therapy with the goal of eradicating clinically and radiographically occult micrometastatic disease that may develop into frank metastatic disease if left untreated. Selection of adjuvant systemic therapies is based on risk stratification of the patient. Two factors affect risk: disease burden (number of lymph nodes, size of the primary tumor) and disease biology as determined by HR and HER2 status, and genomic assays. While patients with triple negative and HER2 positive cancers are generally considered to be high risk, there is considerable biologic diversity among those with HR positive, HER2 negative cancers. Based on trials demonstrating a small but statistically significant benefit for treatment of HR positive, HER 2 negative, node-negative breast cancers with chemotherapy in addition to endocrine therapy, chemotherapy has been standard for healthy women in this group. ${ }^{89}$ Commercially available genomic assays including Oncotype DX (Genomic Health, Redwood City, CA, USA) and Mammaprint (Agendia, Irvine, CA, USA) examine cancerrelated genes in tumor-derived DNA to determine risk of recurrence and potential chemotherapy benefit. These commercially available tests have given clinicians more clarity on which patients should receive chemotherapy.

\section{Chemotherapy}

In high-risk patients, systemic chemotherapy is generally recommended. There are several standard chemotherapy options, typically containing both an anthracycline and a taxane. In the United States, doxorubicin and cyclophosphamide for 4 cycles followed by paclitaxel for 4 cycles (AC-T) is a common regimen. Dose-dense (dd) AC-T given every 2 weeks with growth factor support after each chemotherapy cycle is superior to an older schedule of every 3 weeks..$^{90}$ Other optimal schedules of AC followed by a taxane include weekly paclitaxel for 12 weeks or every 3 weekly docetaxel for 4 cycles. ${ }^{91,92}$ Another standard option is DAC, docetaxel with AC; however, this is not superior to the above regimens, and docetaxel is associated with more toxicity than paclitaxel and higher febrile neutropenia rates in particular. ${ }^{93}$

Meta-analyses have demonstrated the benefit of adjuvant chemotherapy in reducing recurrence and breast cancer mortality, with a greater magnitude of benefit in those with HR negative disease. ${ }^{94}$ Berry et al analyzed trial data from Cancer and Leukemia Group B and US Breast Cancer Intergroup and demonstrated that chemotherapy provided 21-25\% relative 
risk reduction in patients with $\mathrm{HR}$ negative cancer, compared with 8-12\% relative risk reduction in those with HR positive disease ${ }^{95}$ For patients with HR positive, node-negative breast cancer, Oncotype DX provides an estimate of chemotherapy benefit. Patients with high Oncotype recurrence scores $(231)$ have a large reduction in risk of recurrence with chemotherapy (relative risk [RR] 0.26), while those with low scores derive minimal, if any benefit from chemotherapy. ${ }^{96}$ There is insufficient evidence to provide a unanimous recommendation on the adjuvant treatment of patients with intermediate-risk Oncotype recurrence scores, pending the results of the TAILORx (Trial Assigning Individualized Options for Treatment) trial (Figure 2). In this trial, patients with Oncotype recurrence scores of 11-25 were randomized to treatment with endocrine therapy alone or endocrine therapy plus chemotherapy. Chemotherapy for patients in this group may consist of anthracycline-containing or anthracycline-sparing regimens. In patients with low Oncotype recurrence scores, especially scores under 11 , endocrine therapy alone is sufficient. These patients have an excellent outcome, with a 5-year overall survival of $98 \%$ with endocrine therapy alone..$^{97}$

Patients with node-positive breast cancer are generally recommended chemotherapy due to their worse prognosis relative to patients with node-negative breast cancer. This recommendation has been called into question by some retrospective analyses; Albain et al demonstrated absence of chemotherapy benefit in patients with HR positive, lymph nodepositive breast cancer with low Oncotype RS score in the Southwest Oncology Group (SWOG) 8814 study. ${ }^{98}$ This finding led to the development of the RxPONDER ( $R x$ for Positive Node, Endocrine Responsive Breast Cancer) trial (Figure 3), which enrolled patients with HR positive breast cancer with 1-3 positive nodes and Oncotype RS $\leq 25$ and randomized them to chemotherapy versus none; all received standard endocrine therapy. Results of this study will determine whether some patients with node-positive disease may be spared chemotherapy.

\section{Biologic and targeted therapies}

Patients with HER 2 positive breast cancer are given HER2 targeted therapy in combination with a chemotherapy backbone. The availability of HER 2 targeted agents has dramatically changed the prognosis of patients with HER2 positive breast cancers. Initial trials randomizing patients to chemotherapy alone or chemotherapy plus trastuzumab, a monoclonal antibody directed against the HER2 receptor, demonstrated nearly 50\% reduction in rate of recurrence. ${ }^{99-104}$ At present, patients with stage I HER2 positive breast cancer often receive a regimen of paclitaxel $(\mathrm{T})$ with trastuzumab $(\mathrm{H}) .{ }^{105}$ Until United States Food and Drug Administration approval of pertuzumab (P) in 2013, patients with stage II-III HER2 positive breast cancer received regimens with trastuzumab added to AC-T (AC-TH) or to docetaxel and carboplatin $(\mathrm{DCbH})$. Recent data have shown an improvement in pathologic complete response rate when pertuzumab, an HER2 dimerization inhibitor, is added to trastuzumab in the neoadjuvant setting. Administration of dual-HER2 agents (HP) in the neoadjuvant setting is now standard for patients with stage II-III HER2 positive breast cancer. ${ }^{106,107}$ The National Comprehensive Cancer Network has also endorsed the addition of HP to chemotherapy for patients with the same burden of disease in the adjuvant setting if these therapies were not received neoadjuvantly. Recently the APHINITY trial demonstrated 
a small but statistically significant benefit of adjuvant HP-based over H-based therapy for one year. $^{108}$

\section{Endocrine therapy}

Endocrine therapy is recommended for most patients with HR positive disease. Patients may be treated with endocrine therapy for 5-10 years, and possibly longer. Five years of adjuvant tamoxifen reduces risk of recurrence by nearly $50 \%$ during years $0-4$, with continued risk reduction of over $30 \%$ in years 5-9. Furthermore, yearly breast cancer mortality was reduced by $30 \%$ during the first 15 years. ${ }^{109}$ In patients who took 10 versus 5 years of tamoxifen, longer duration of therapy led to further reduction in recurrence (by about 25\%) and breast cancer mortality (by almost 30\%), most notably after year $10 .{ }^{110}$ After 5 years of tamoxifen, an additional 5 years of aromatase inhibitors provides an additional $40 \%$ relative risk reduction in recurrence as demonstrated by the MA.17 trial. ${ }^{111}$ MA.17R randomized patients on 5 years of aromatase inhibitor (AI) (some also had prior tamoxifen) to an additional 5 years of AI versus placebo, and demonstrated a 34\% risk reduction in recurrence with 10 years of AI. ${ }^{112}$ Thus, longer duration of therapy confers additional benefit.

Tamoxifen is used in premenopausal and postmenopausal women; aromatase inhibitors (anastrozole, letrozole, and exemestane) are only used in postmenopausal women and are generally preferred over tamoxifen as adjuvant therapy, but may also be prescribed sequentially with tamoxifen. ${ }^{113}$ Common side effects of these medications include hot flashes, vaginal dryness, arthralgia, and myalgia. Tamoxifen increases the risk of venous thromboembolic events and uterine cancers, and aromatase inhibitors may accelerate osteopenia and osteoporosis, and are associated with more musculoskeletal symptoms. In premenopausal patients with high-risk HR positive breast cancer, ovarian function suppression with AI or with tamoxifen is more effective than tamoxifen alone. ${ }^{114}$

\section{Special considerations}

Before beginning chemotherapy, assessment of a premenopausal patient's wishes for future pregnancy is vital, as chemotherapy for breast cancer may cause premature ovarian failure. Options for fertility preservation include oocyte preservation, embryo preservation, and gonadotropin-releasing hormone (GNRH) agonist use during chemotherapy for ovarian protection. Consultation with a reproductive endocrinologist before breast cancer treatment is suggested for young women desiring future fertility, although oocyte and embryo preservation may be financially burdensome. The administration of GNRH agonists during chemotherapy is safe and inexpensive, and in one study, reduced the risk of premature ovarian failure in women under 50 years of age from $22 \%$ to $8 \% .{ }^{115}$ Pregnancy after breast cancer does not appear to negatively impact survival. ${ }^{116}$

Patients with HR positive ductal carcinoma in situ may be offered endocrine therapy to reduce the likelihood of a future breast cancer in the affected breast if conserved, and in the contralateral breast. Tamoxifen and aromatase inhibitors are both options. ${ }^{117,118}$ 
The management of breast cancer in elderly women is highly individualized and requires collaboration across disciplines (medical oncology, surgical oncology, and radiation oncology). A comprehensive assessment of performance status, comorbidities, and lifeexpectancy is critical. In patients older than 65 years of age deemed fit for chemotherapy, standard chemotherapy regimens are superior to capecitabine monotherapy. ${ }^{119}$

\section{Surveillance}

Surveillance after adjuvant therapy for breast cancer is comprised primarily of history, physical exam, and annual mammography. Routine computed tomography or positron emission tomography imaging in the absence of symptoms has not been shown to improve survival; there is currently no proven role for "surveillance" imaging. ${ }^{120}$ Serum tumor markers (CA 15-3 and CEA) are non-specific and may prompt unnecessary imaging and procedures; they have no role in post-adjuvant therapy surveillance in an asymptomatic patient. ${ }^{121}$ After a breast cancer diagnosis, patients should be encouraged to make lifestyle modifications that can decrease their likelihood of recurrence, including maintaining a normal body mass index. ${ }^{122}$ Of note, there are emerging observational data demonstrating that physical activity may reduce the risk of breast cancer-specific recurrence and mortality, but definitive prospective studies are needed ${ }^{123,124}$

\section{Summary}

Patients receive adjuvant systemic therapies in addition to local therapy to treat micrometastatic disease and prevent distant recurrence. Adjuvant therapy is tailored to the patient's risk of recurrence, and may include chemotherapy, biologic therapy, and endocrine therapy. Following adjuvant systemic treatment, there is currently no role for routine crosssectional imaging in the absence of symptoms. Novel modalities for early tumor detection are welcomed, but will need to demonstrate clinical utility in prospective trials.

\section{Acknowledgments}

Dr. Monica Morrow is a consultant for Genomic Health. Dr. Chau Dang receives research funding from Roche/ Genentech and PUMA.

\section{References}

1. Hortobagyi GN, Buzdar AU. Management of locally advanced breast cancer. Am J Clin Oncol. 1988; 11(5):597-601. [PubMed: 2845771]

2. Fisher B, Anderson S, Bryant J, Margolese RG, Deutsch M, Fisher ER, et al. Twenty-year follow-up of a randomized trial comparing total mastectomy, lumpectomy, and lumpectomy plus irradiation for the treatment of invasive breast cancer. N Engl J Med. 2002; 347(16):1233-41. [PubMed: 12393820]

3. Veronesi U, Cascinelli N, Mariani L, Greco M, Saccozzi R, Luini A, et al. Twenty-year follow-up of a randomized study comparing breast-conserving surgery with radical mastectomy for early breast cancer. N Engl J Med. 2002; 347(16):1227-32. [PubMed: 12393819]

4. Poggi MM, Danforth DN, Sciuto LC, Smith SL, Steinberg SM, Liewehr DJ, et al. Eighteen-year results in the treatment of early breast carcinoma with mastectomy versus breast conservation therapy: the National Cancer Institute Randomized Trial. Cancer. 2003; 98(4):697-702. [PubMed: 12910512] 
5. Voogd AC, Nielsen M, Peterse JL, Blichert-Toft M, Bartelink H, Overgaard M, et al. Differences in risk factors for local and distant recurrence after breast-conserving therapy or mastectomy for stage I and II breast cancer: pooled results of two large European randomized trials. J Clin Oncol. 2001; 19(6):1688-97. [PubMed: 11250998]

6. Darby S, McGale P, Correa C, Taylor C, Arriagada R, Clarke M, et al. Effect of radiotherapy after breast-conserving surgery on 10-year recurrence and 15-year breast cancer death: meta-analysis of individual patient data for 10,801 women in 17 randomised trials. Lancet. 2011; 378(9804):170716. [PubMed: 22019144]

7. van Dongen JA, Voogd AC, Fentiman IS, Legrand C, Sylvester RJ, Tong D, et al. Long-term results of a randomized trial comparing breast-conserving therapy with mastectomy: European Organization for Research and Treatment of Cancer 10801 trial. J Natl Cancer Inst. 2000; 92(14): 1143-50. [PubMed: 10904087]

8. Wapnir IL, Anderson SJ, Mamounas EP, Geyer CE Jr, Jeong JH, Tan-Chiu E, et al. Prognosis after ipsilateral breast tumor recurrence and locoregional recurrences in five National Surgical Adjuvant Breast and Bowel Project node-positive adjuvant breast cancer trials. J Clin Oncol. 2006; 24(13): 2028-37. [PubMed: 16648502]

9. Anderson SJ, Wapnir I, Dignam JJ, Fisher B, Mamounas EP, Jeong JH, et al. Prognosis after ipsilateral breast tumor recurrence and locoregional recurrences in patients treated by breastconserving therapy in five National Surgical Adjuvant Breast and Bowel Project protocols of nodenegative breast cancer. J Clin Oncol. 2009; 27(15):2466-73. [PubMed: 19349544]

10. Clarke M, Collins R, Darby S, Davies C, Elphinstone P, Evans V, et al. Effects of radiotherapy and of differences in the extent of surgery for early breast cancer on local recurrence and 15-year survival: an overview of the randomised trials. Lancet. 2005; 366(9503):2087-106. [PubMed: 16360786]

11. Voduc KD, Cheang MC, Tyldesley S, Gelmon K, Nielsen TO, Kennecke H. Breast cancer subtypes and the risk of local and regional relapse. J Clin Oncol. 2010; 28(10):1684-91. [PubMed: 20194857]

12. Lowery AJ, Kell MR, Glynn RW, Kerin MJ, Sweeney KJ. Locoregional recurrence after breast cancer surgery: a systematic review by receptor phenotype. Breast Cancer Res Treat. 2012; 133(3): 831-41. [PubMed: 22147079]

13. Network NCC. Clinical Practice Guidelines Oncology - Breast Cancer (Version 2.2017). 2017. [July 24, 2017]; Available from: https://www.nccn.org/professionals/physician_gls/pdf/breast.pdf

14. Moran MS, Schnitt SJ, Giuliano AE, Harris JR, Khan SA, Horton J, et al. Society of Surgical Oncology-American Society for Radiation Oncology consensus guideline on margins for breastconserving surgery with whole-breast irradiation in stages I and II invasive breast cancer. J Clin Oncol. 2014; 32(14):1507-15. [PubMed: 24516019]

15. Houssami N, Macaskill P, Marinovich ML, Morrow M. The association of surgical margins and local recurrence in women with early-stage invasive breast cancer treated with breast-conserving therapy: a meta-analysis. Ann Surg Oncol. 2014; 21(3):717-30. [PubMed: 24473640]

16. Kuchenbaecker KB, Hopper JL, Barnes DR, Phillips KA, Mooij TM, Roos-Blom MJ, et al. Risks of Breast, Ovarian, and Contralateral Breast Cancer for BRCA1 and BRCA2 Mutation Carriers. Jama. 2017; 317(23):2402-16. [PubMed: 28632866]

17. Morrow M, Jagsi R, Alderman AK, Griggs JJ, Hawley ST, Hamilton AS, et al. Surgeon recommendations and receipt of mastectomy for treatment of breast cancer. Jama. 2009; 302(14): 1551-6. [PubMed: 19826024]

18. Houssami N, Ciatto S, Macaskill P, Lord SJ, Warren RM, Dixon JM, et al. Accuracy and surgical impact of magnetic resonance imaging in breast cancer staging: systematic review and metaanalysis in detection of multifocal and multicentric cancer. J Clin Oncol. 2008; 26(19):3248-58. [PubMed: 18474876]

19. Katipamula R, Degnim AC, Hoskin T, Boughey JC, Loprinzi C, Grant CS, et al. Trends in mastectomy rates at the Mayo Clinic Rochester: effect of surgical year and preoperative magnetic resonance imaging. J Clin Oncol. 2009; 27(25):4082-8. [PubMed: 19636020]

20. King TA, Sakr R, Patil S, Gurevich I, Stempel M, Sampson M, et al. Clinical management factors contribute to the decision for contralateral prophylactic mastectomy. J Clin Oncol. 2011; 29(16): 2158-64. [PubMed: 21464413] 
21. Sorbero ME, Dick AW, Beckjord EB, Ahrendt G. Diagnostic breast magnetic resonance imaging and contralateral prophylactic mastectomy. Ann Surg Oncol. 2009; 16(6):1597-605. [PubMed: 19330381]

22. Fancellu A, Soro D, Castiglia P, Marras V, Melis M, Cottu P, et al. Usefulness of magnetic resonance in patients with invasive cancer eligible for breast conservation: a comparative study. Clin Breast Cancer. 2014; 14(2):114-21. [PubMed: 24321101]

23. Pilewskie M, King TA. Magnetic resonance imaging in patients with newly diagnosed breast cancer: a review of the literature. Cancer. 2014; 120(14):2080-9. [PubMed: 24752817]

24. Houssami N, Turner R, Macaskill P, Turnbull LW, McCready DR, Tuttle TM, et al. An individual person data meta-analysis of preoperative magnetic resonance imaging and breast cancer recurrence. J Clin Oncol. 2014; 32(5):392-401. [PubMed: 24395846]

25. Turnbull L, Brown S, Harvey I, Olivier C, Drew P, Napp V, et al. Comparative effectiveness of MRI in breast cancer (COMICE) trial: a randomised controlled trial. Lancet. 2010; 375(9714): 563-71. [PubMed: 20159292]

26. Peters NH, van Esser S, van den Bosch MA, Storm RK, Plaisier PW, van Dalen T, et al. Preoperative MRI and surgical management in patients with nonpalpable breast cancer: the MONET - randomised controlled trial. Eur J Cancer. 2011; 47(6):879-86. [PubMed: 21195605]

27. Houssami N, Turner RM, Morrow M. Meta-analysis of pre-operative magnetic resonance imaging (MRI) and surgical treatment for breast cancer. Breast Cancer Res Treat. 2017

28. Chen AM, Obedian E, Haffty BG. Breast-conserving therapy in the setting of collagen vascular disease. Cancer J. 2001; 7(6):480-91. [PubMed: 11769860]

29. Phan C, Mindrum M, Silverman C, Paris K, Spanos W. Matched-control retrospective study of the acute and late complications in patients with collagen vascular diseases treated with radiation therapy. Cancer J. 2003; 9(6):461-6. [PubMed: 14740974]

30. Lin A, Abu-Isa E, Griffith KA, Ben-Josef E. Toxicity of radiotherapy in patients with collagen vascular disease. Cancer. 2008; 113(3):648-53. [PubMed: 18506734]

31. Holland R, Veling SH, Mravunac M, Hendriks JH. Histologic multifocality of Tis, T1-2 breast carcinomas. Implications for clinical trials of breast-conserving surgery. Cancer. 1985; 56(5):97990. [PubMed: 2990668]

32. Hopwood P, Haviland JS, Sumo G, Mills J, Bliss JM, Yarnold JR. Comparison of patient-reported breast, arm, and shoulder symptoms and body image after radiotherapy for early breast cancer: 5year follow-up in the randomised Standardisation of Breast Radiotherapy (START) trials. Lancet Oncol. 2010; 11(3):231-40. [PubMed: 20138809]

33. Haviland JS, Owen JR, Dewar JA, Agrawal RK, Barrett J, Barrett-Lee PJ, et al. The UK Standardisation of Breast Radiotherapy (START) trials of radiotherapy hypofractionation for treatment of early breast cancer: 10-year follow-up results of two randomised controlled trials. Lancet Oncol. 2013; 14(11):1086-94. [PubMed: 24055415]

34. Whelan TJ, Pignol JP, Levine MN, Julian JA, MacKenzie R, Parpia S, et al. Long-term results of hypofractionated radiation therapy for breast cancer. N Engl J Med. 2010; 362(6):513-20. [PubMed: 20147717]

35. Hughes KS, Schnaper LA, Bellon JR, Cirrincione CT, Berry DA, McCormick B, et al. Lumpectomy plus tamoxifen with or without irradiation in women age 70 years or older with early breast cancer: long-term follow-up of CALGB 9343. J Clin Oncol. 2013; 31(19):2382-7. [PubMed: 23690420]

36. Kunkler IH, Williams LJ, Jack WJ, Cameron DA, Dixon JM. Breast-conserving surgery with or without irradiation in women aged 65 years or older with early breast cancer (PRIME II): a randomised controlled trial. Lancet Oncol. 2015; 16(3):266-73. [PubMed: 25637340]

37. Engel J, Kerr J, Schlesinger-Raab A, Sauer H, Holzel D. Quality of life following breastconserving therapy or mastectomy: results of a 5-year prospective study. Breast J. 2004; 10(3): 223-31. [PubMed: 15125749]

38. Hartl K, Janni W, Kastner R, Sommer H, Strobl B, Rack B, et al. Impact of medical and demographic factors on long-term quality of life and body image of breast cancer patients. Ann Oncol. 2003; 14(7):1064-71. [PubMed: 12853348] 
39. Arndt V, Stegmaier C, Ziegler H, Brenner H. Quality of life over 5 years in women with breast cancer after breast-conserving therapy versus mastectomy: a population-based study. J Cancer Res Clin Oncol. 2008; 134(12):1311-8. [PubMed: 18504613]

40. Jagsi R, Li Y, Morrow M, Janz N, Alderman A, Graff J, et al. Patient-reported Quality of Life and Satisfaction With Cosmetic Outcomes After Breast Conservation and Mastectomy With and Without Reconstruction: Results of a Survey of Breast Cancer Survivors. Ann Surg. 2015; 261(6): 1198-206. [PubMed: 25654742]

41. Bulstrode NW, Shrotria S. Prediction of cosmetic outcome following conservative breast surgery using breast volume measurements. The Breast. 2001; 10(2):124-6. [PubMed: 14965571]

42. Tenofsky PL, Dowell P, Topalovski T, Helmer SD. Surgical, oncologic, and cosmetic differences between oncoplastic and nononcoplastic breast conserving surgery in breast cancer patients. The American Journal of Surgery. 2014; 207(3):398-402. [PubMed: 24581764]

43. Rietjens M, Urban CA, Rey PC, Mazzarol G, Maisonneuve P, Garusi C, et al. Long-term oncological results of breast conservative treatment with oncoplastic surgery. The Breast. 2007; 16(4):387-95. [PubMed: 17376687]

44. Meretoja TJ, Rasia S, von Smitten KA, Asko-Seljavaara SL, Kuokkanen HO, Jahkola TA. Late results of skin-sparing mastectomy followed by immediate breast reconstruction. Br J Surg. 2007; 94(10):1220-5. [PubMed: 17579346]

45. Medina-Franco H, Vasconez LO, Fix RJ, Heslin MJ, Beenken SW, Bland KI, et al. Factors associated with local recurrence after skin-sparing mastectomy and immediate breast reconstruction for invasive breast cancer. Ann Surg. 2002; 235(6):814-9. [PubMed: 12035037]

46. Carlson GW, Styblo TM, Lyles RH, Jones G, Murray DR, Staley CA, et al. The use of skin sparing mastectomy in the treatment of breast cancer: The Emory experience. Surg Oncol. 2003; 12(4): 265-9. [PubMed: 14998566]

47. Lanitis S, Tekkis PP, Sgourakis G, Dimopoulos N, Al Mufti R, Hadjiminas DJ. Comparison of skin-sparing mastectomy versus non-skin-sparing mastectomy for breast cancer: a meta-analysis of observational studies. Ann Surg. 2010; 251(4):632-9. [PubMed: 20224371]

48. Smith BL, Tang R, Rai U, Plichta JK, Colwell AS, Gadd MA, et al. Oncologic Safety of NippleSparing Mastectomy in Women with Breast Cancer. J Am Coll Surg. 2017

49. Moo TA, Pinchinat T, Mays S, Landers A, Christos P, Alabdulkareem H, et al. Oncologic Outcomes After Nipple-Sparing Mastectomy. Ann Surg Oncol. 2016; 23(10):3221-5. [PubMed: 27380643]

50. de Alcantara Filho P, Capko D, Barry JM, Morrow M, Pusic A, Sacchini VS. Nipple-sparing mastectomy for breast cancer and risk-reducing surgery: the Memorial Sloan-Kettering Cancer Center experience. Ann Surg Oncol. 2011; 18(11):3117-22. [PubMed: 21847697]

51. Orzalesi L, Casella D, Santi C, Cecconi L, Murgo R, Rinaldi S, et al. Nipple sparing mastectomy: Surgical and oncological outcomes from a national multicentric registry with 913 patients (1006 cases) over a six year period. Breast. 2016; 25:75-81. [PubMed: 26612083]

52. Recht A, Gray R, Davidson NE, Fowble BL, Solin LJ, Cummings FJ, et al. Locoregional failure 10 years after mastectomy and adjuvant chemotherapy with or without tamoxifen without irradiation: experience of the Eastern Cooperative Oncology Group. J Clin Oncol. 1999; 17(6):1689-700. [PubMed: 10561205]

53. Overgaard M, Jensen MB, Overgaard J, Hansen PS, Rose C, Andersson M, et al. Postoperative radiotherapy in high-risk postmenopausal breast-cancer patients given adjuvant tamoxifen: Danish Breast Cancer Cooperative Group DBCG 82c randomised trial. Lancet. 1999; 353(9165):1641-8. [PubMed: 10335782]

54. Recht A, Edge SB, Solin LJ, Robinson DS, Estabrook A, Fine RE, et al. Postmastectomy radiotherapy: clinical practice guidelines of the American Society of Clinical Oncology. J Clin Oncol. 2001; 19(5):1539-69. [PubMed: 11230499]

55. Moo TA, McMillan R, Lee M, Stempel M, Patil S, Ho A, et al. Selection criteria for postmastectomy radiotherapy in t1-t 2 tumors with 1 to 3 positive lymph nodes. Ann Surg Oncol. 2013; 20(10):3169-74. [PubMed: 23975289] 
56. Sharma R, Bedrosian I, Lucci A, Hwang RF, Rourke LL, Qiao W, et al. Present-day locoregional control in patients with $\mathrm{t} 1$ or $\mathrm{t} 2$ breast cancer with 0 and 1 to 3 positive lymph nodes after mastectomy without radiotherapy. Ann Surg Oncol. 2010; 17(11):2899-908. [PubMed: 20443145]

57. EBCTCG. McGale P, Taylor C, Correa C, Cutter D, Duane F, et al. Effect of radiotherapy after mastectomy and axillary surgery on 10-year recurrence and 20-year breast cancer mortality: metaanalysis of individual patient data for 8135 women in 22 randomised trials. Lancet. 2014; 383(9935):2127-35. [PubMed: 24656685]

58. Recht A, Comen EA, Fine RE, Fleming GF, Hardenbergh PH, Ho AY, et al. Postmastectomy Radiotherapy: An American Society of Clinical Oncology, American Society for Radiation Oncology, and Society of Surgical Oncology Focused Guideline Update. J Clin Oncol. 2016; 34(36):4431-42. [PubMed: 27646947]

59. Hoffman KE, Mittendorf EA, Buchholz TA. Optimising radiation treatment decisions for patients who receive neoadjuvant chemotherapy and mastectomy. Lancet Oncol. 2012; 13(6):e270-6. [PubMed: 22652235]

60. McCartan D, Stempel M, Eaton A, Morrow M, Pilewskie M. Impact of Body Mass Index on Clinical Axillary Nodal Assessment in Breast Cancer Patients. Ann Surg Oncol. 2016; 23(10): 3324-9. [PubMed: 27338746]

61. Kern KA. Concordance and validation study of sentinel lymph node biopsy for breast cancer using subareolar injection of blue dye and technetium 99m sulfur colloid. J Am Coll Surg. 2002; 195(4): 467-75. [PubMed: 12375751]

62. Kern KA. Sentinel lymph node mapping in breast cancer using subareolar injection of blue dye. Journal of the American College of Surgeons. 1999; 189(6):539-45. [PubMed: 10589589]

63. Mertz L, Mathelin C, Marin C, Gairard B, Chenard MP, Brettes JP, et al. Subareolar injection of 99m-Tc sulfur colloid for sentinel nodes identification in multifocal invasive breast cancer. Bull Cancer. 1999; 86(11):939-45. [PubMed: 10586110]

64. Boolbol SK, Fey JV, Borgen PI, Heerdt AS, Montgomery LL, Paglia M, et al. Intradermal isotope injection: a highly accurate method of lymphatic mapping in breast carcinoma. Ann Surg Oncol. 2001; 8(1):20-4. [PubMed: 11206219]

65. Krag D, Weaver D, Ashikaga T, Moffat F, Klimberg VS, Shriver C, et al. The sentinel node in breast cancer-a multicenter validation study. N Engl J Med. 1998; 339(14):941-6. [PubMed: 9753708]

66. Veronesi U, Viale G, Paganelli G, Zurrida S, Luini A, Galimberti V, et al. Sentinel lymph node biopsy in breast cancer: ten-year results of a randomized controlled study. Ann Surg. 2010; 251(4): 595-600. [PubMed: 20195151]

67. Van Zee KJ, Manasseh DM, Bevilacqua JL, Boolbol SK, Fey JV, Tan LK, et al. A nomogram for predicting the likelihood of additional nodal metastases in breast cancer patients with a positive sentinel node biopsy. Ann Surg Oncol. 2003; 10(10):1140-51. [PubMed: 14654469]

68. Weiser MR, Montgomery LL, Tan LK, Susnik B, Leung DY, Borgen PI, et al. Lymphovascular invasion enhances the prediction of non-sentinel node metastases in breast cancer patients with positive sentinel nodes. Ann Surg Oncol. 2001; 8(2):145-9. [PubMed: 11258779]

69. Hwang RF, Krishnamurthy S, Hunt KK, Mirza N, Ames FC, Feig B, et al. Clinicopathologic factors predicting involvement of nonsentinel axillary nodes in women with breast cancer. Ann Surg Oncol. 2003; 10(3):248-54. [PubMed: 12679309]

70. Giuliano AE, Hunt KK, Ballman KV, Beitsch PD, Whitworth PW, Blumencranz PW, et al. Axillary dissection vs no axillary dissection in women with invasive breast cancer and sentinel node metastasis: a randomized clinical trial. Jama. 2011; 305(6):569-75. [PubMed: 21304082]

71. Giuliano AE, Ballman K, McCall L, Beitsch P, Whitworth PW, Blumencranz P, et al. Locoregional Recurrence After Sentinel Lymph Node Dissection With or Without Axillary Dissection in Patients With Sentinel Lymph Node Metastases: Long-term Follow-up From the American College of Surgeons Oncology Group (Alliance) ACOSOG Z0011 Randomized Trial. Ann Surg. 2016; 264(3):413-20. [PubMed: 27513155]

72. Giuliano AE, Ballman KV, McCall L, Beitsch PD, Brennan MB, Kelemen PR, et al. Effect of Axillary Dissection vs No Axillary Dissection on 10-Year Overall Survival Among Women With 
Invasive Breast Cancer and Sentinel Node Metastasis: The ACOSOG Z0011 (Alliance)

Randomized Clinical Trial. Jama. 2017; 318(10):918-26. [PubMed: 28898379]

73. Dengel LT, Van Zee KJ, King TA, Stempel M, Cody HS, El-Tamer M, et al. Axillary dissection can be avoided in the majority of clinically node-negative patients undergoing breast-conserving therapy. Ann Surg Oncol. 2014; 21(1):22-7. [PubMed: 23975314]

74. Donker M, Slaets L, van Tienhoven G, Rutgers EJ. Axillary lymph node dissection versus axillary radiotherapy in patients with a positive sentinel node: the AMAROS trial. Ned Tijdschr Geneeskd. 2015; 159:A9302. [PubMed: 26488192]

75. Morrow M, Van Zee KJ, Patil S, Petruolo O, Mamtani A, Barrio AV, et al. Axillary Dissection and Nodal Irradiation Can Be Avoided for Most Node-positive Z0011-eligible Breast Cancers: A Prospective Validation Study of 793 Patients. Ann Surg. 2017; 266(3):457-62. [PubMed: 28650355]

76. Pilewskie M, Jochelson M, Gooch JC, Patil S, Stempel M, Morrow M. Is Preoperative Axillary Imaging Beneficial in Identifying Clinically Node-Negative Patients Requiring Axillary Lymph Node Dissection? J Am Coll Surg. 2016; 222(2):138-45. [PubMed: 26711795]

77. Pilewskie M, Mautner SK, Stempel M, Eaton A, Morrow M. Does a Positive Axillary Lymph Node Needle Biopsy Result Predict the Need for an Axillary Lymph Node Dissection in Clinically Node-Negative Breast Cancer Patients in the ACOSOG Z0011 Era? Ann Surg Oncol. 2016; 23(4): 1123-8. [PubMed: 26553439]

78. van der Hage JA, van de Velde CJ, Julien JP, Tubiana-Hulin M, Vandervelden C, Duchateau L. Preoperative chemotherapy in primary operable breast cancer: results from the European Organization for Research and Treatment of Cancer trial 10902. J Clin Oncol. 2001; 19(22):422437. [PubMed: 11709566]

79. Broet P, Scholl SM, de la Rochefordiere A, Fourquet A, Moreau T, De Rycke Y, et al. Short and long-term effects on survival in breast cancer patients treated by primary chemotherapy: an updated analysis of a randomized trial. Breast Cancer Res Treat. 1999; 58(2):151-6. [PubMed: 10674880]

80. Fisher B, Bryant J, Wolmark N, Mamounas E, Brown A, Fisher ER, et al. Effect of preoperative chemotherapy on the outcome of women with operable breast cancer. J Clin Oncol. 1998; 16(8): 2672-85. [PubMed: 9704717]

81. Mieog JS, van der Hage JA, van de Velde CJ. Neoadjuvant chemotherapy for operable breast cancer. Br J Surg. 2007; 94(10):1189-200. [PubMed: 17701939]

82. Jochelson MS, Lampen-Sachar K, Gibbons G, Dang C, Lake D, Morris EA, et al. Do MRI and mammography reliably identify candidates for breast conservation after neoadjuvant chemotherapy? Ann Surg Oncol. 2015; 22(5):1490-5. [PubMed: 25777093]

83. Feliciano Y, Mamtani A, Morrow M, Stempel MM, Patil S, Jochelson MS. Do Calcifications Seen on Mammography After Neoadjuvant Chemotherapy for Breast Cancer Always Need to Be Excised? Ann Surg Oncol. 2017; 24(6):1492-8. [PubMed: 28058550]

84. Classe JM, Bordes V, Campion L, Mignotte H, Dravet F, Leveque J, et al. Sentinel lymph node biopsy after neoadjuvant chemotherapy for advanced breast cancer: results of Ganglion Sentinelle et Chimiotherapie Neoadjuvante, a French prospective multicentric study. J Clin Oncol. 2009; 27(5):726-32. [PubMed: 19114697]

85. Xing Y, Foy M, Cox DD, Kuerer HM, Hunt KK, Cormier JN. Meta-analysis of sentinel lymph node biopsy after preoperative chemotherapy in patients with breast cancer. Br J Surg. 2006; 93(5): 539-46. [PubMed: 16329089]

86. Kelly AM, Dwamena B, Cronin P, Carlos RC. Breast cancer sentinel node identification and classification after neoadjuvant chemotherapy-systematic review and meta analysis. Acad Radiol. 2009; 16(5):551-63. [PubMed: 19345896]

87. Hunt KK, Yi M, Mittendorf EA, Guerrero C, Babiera GV, Bedrosian I, et al. Sentinel lymph node surgery after neoadjuvant chemotherapy is accurate and reduces the need for axillary dissection in breast cancer patients. Ann Surg. 2009; 250(4):558-66. [PubMed: 19730235]

88. Mamtani A, Barrio AV, King TA, Van Zee KJ, Plitas G, Pilewskie M, et al. How Often Does Neoadjuvant Chemotherapy Avoid Axillary Dissection in Patients With Histologically Confirmed 
Nodal Metastases? Results of a Prospective Study. Ann Surg Oncol. 2016; 23(11):3467-74. [PubMed: 27160528]

89. Early Breast Cancer Trialists' Collaborative G. Effects of chemotherapy and hormonal therapy for early breast cancer on recurrence and 15-year survival: an overview of the randomised trials. Lancet. 2005; 365(9472):1687-717. [PubMed: 15894097]

90. Citron ML, Berry DA, Cirrincione C, Hudis C, Winer EP, Gradishar WJ, et al. Randomized trial of dose-dense versus conventionally scheduled and sequential versus concurrent combination chemotherapy as postoperative adjuvant treatment of node-positive primary breast cancer: first report of Intergroup Trial C9741/Cancer and Leukemia Group B Trial 9741. J Clin Oncol. 2003; 21(8):1431-9. [PubMed: 12668651]

91. Sparano JA, Wang M, Martino S, Jones V, Perez EA, Saphner T, et al. Weekly paclitaxel in the adjuvant treatment of breast cancer. N Engl J Med. 2008; 358(16):1663-71. [PubMed: 18420499]

92. Sparano JA, Zhao F, Martino S, Ligibel JA, Perez EA, Saphner T, et al. Long-Term Follow-Up of the E1199 Phase III Trial Evaluating the Role of Taxane and Schedule in Operable Breast Cancer. J Clin Oncol. 2015; 33(21):2353-60. [PubMed: 26077235]

93. Swain SM, Tang G, Geyer CE Jr, Rastogi P, Atkins JN, Donnellan PP, et al. Definitive results of a phase III adjuvant trial comparing three chemotherapy regimens in women with operable, nodepositive breast cancer: the NSABP B-38 trial. J Clin Oncol. 2013; 31(26):3197-204. [PubMed: 23940225]

94. Early Breast Cancer Trialists' Collaborative G. Peto R, Davies C, Godwin J, Gray R, Pan HC, et al. Comparisons between different polychemotherapy regimens for early breast cancer: meta-analyses of long-term outcome among 100,000 women in 123 randomised trials. Lancet. 2012; 379(9814): 432-44. [PubMed: 22152853]

95. Berry DA, Cirrincione C, Henderson IC, Citron ML, Budman DR, Goldstein LJ, et al. Estrogenreceptor status and outcomes of modern chemotherapy for patients with node-positive breast cancer. Jama. 2006; 295(14):1658-67. [PubMed: 16609087]

96. Paik S, Tang G, Shak S, Kim C, Baker J, Kim W, et al. Gene expression and benefit of chemotherapy in women with node-negative, estrogen receptor-positive breast cancer. J Clin Oncol. 2006; 24(23):3726-34. [PubMed: 16720680]

97. Sparano JA, Gray RJ, Makower DF, Pritchard KI, Albain KS, Hayes DF, et al. Prospective Validation of a 21-Gene Expression Assay in Breast Cancer. N Engl J Med. 2015; 373(21):200514. [PubMed: 26412349]

98. Albain KS, Barlow WE, Shak S, Hortobagyi GN, Livingston RB, Yeh IT, et al. Prognostic and predictive value of the 21-gene recurrence score assay in postmenopausal women with nodepositive, oestrogen-receptor-positive breast cancer on chemotherapy: a retrospective analysis of a randomised trial. Lancet Oncol. 2010; 11(1):55-65. [PubMed: 20005174]

99. Cameron D, Piccart-Gebhart MJ, Gelber RD, Procter M, Goldhirsch A, de Azambuja E, et al. 11 years' follow-up of trastuzumab after adjuvant chemotherapy in HER2-positive early breast cancer: final analysis of the HERceptin Adjuvant (HERA) trial. Lancet. 2017; 389(10075):1195205. [PubMed: 28215665]

100. Perez EA, Romond EH, Suman VJ, Jeong JH, Sledge G, Geyer CE Jr, et al. Trastuzumab plus adjuvant chemotherapy for human epidermal growth factor receptor 2-positive breast cancer: planned joint analysis of overall survival from NSABP B-31 and NCCTG N9831. J Clin Oncol. 2014; 32(33):3744-52. [PubMed: 25332249]

101. Piccart-Gebhart MJ, Procter M, Leyland-Jones B, Goldhirsch A, Untch M, Smith I, et al. Trastuzumab after adjuvant chemotherapy in HER2-positive breast cancer. N Engl J Med. 2005; 353(16):1659-72. [PubMed: 16236737]

102. Romond EH, Perez EA, Bryant J, Suman VJ, Geyer CE Jr, Davidson NE, et al. Trastuzumab plus adjuvant chemotherapy for operable HER2-positive breast cancer. N Engl J Med. 2005; 353(16): 1673-84. [PubMed: 16236738]

103. Slamon D, Eiermann W, Robert N, Pienkowski T, Martin M, Press M, et al. Adjuvant trastuzumab in HER2-positive breast cancer. N Engl J Med. 2011; 365(14):1273-83. [PubMed: 21991949]

104. Slamon DJ, Eiermann W, Robert NJ, Giermek J, Martin M, Jasiowka M. , et al. Ten year followup of the BCIRG-006 trial comparing doxorubicin plus cyclophosphamide followed by docetaxel 
(AC®T) with doxorubicin plus cyclophosphamide followed by docetaxel and trastuzumab (AC®TH) with docetaxel, carboplatin and trastuzumab (TCH) in HER2+ early breast cancer patients. San Antonio Breast Cancer Symposium 2015. Abstract No. S5-04. Presented December 11, 2015. https://www.sabcs.org/Portals/SABCS2016/Documents/SABCS-2015-Abstracts.pdf? v=5 (Accessed September 29, 2017)

105. Tolaney SM, Barry WT, Dang CT, Yardley DA, Moy B, Marcom PK, et al. Adjuvant paclitaxel and trastuzumab for node-negative, HER2-positive breast cancer. N Engl J Med. 2015; 372(2): 134-41. [PubMed: 25564897]

106. Gianni L, Pienkowski T, Im YH, Roman L, Tseng LM, Liu MC, et al. Efficacy and safety of neoadjuvant pertuzumab and trastuzumab in women with locally advanced, inflammatory, or early HER2-positive breast cancer (NeoSphere): a randomised multicentre, open-label, phase 2 trial. Lancet Oncol. 2012; 13(1):25-32. [PubMed: 22153890]

107. Schneeweiss A, Chia S, Hickish T, Harvey V, Eniu A, Hegg R, et al. Pertuzumab plus trastuzumab in combination with standard neoadjuvant anthracycline-containing and anthracycline-free chemotherapy regimens in patients with HER2-positive early breast cancer: a randomized phase II cardiac safety study (TRYPHAENA). Ann Oncol. 2013; 24(9):2278-84. [PubMed: 23704196]

108. von Minckwitz G, Procter M, de Azambuja E, Zardavas D, Benyunes M, Viale G, et al. Adjuvant Pertuzumab and Trastuzumab in Early HER2-Positive Breast Cancer. N Engl J Med. 2017; 377(2):122-31. [PubMed: 28581356]

109. Early Breast Cancer Trialists' Collaborative G. Davies C, Godwin J, Gray R, Clarke M, Cutter D, et al. Relevance of breast cancer hormone receptors and other factors to the efficacy of adjuvant tamoxifen: patient-level meta-analysis of randomised trials. Lancet. 2011; 378(9793):771-84. [PubMed: 21802721]

110. Davies C, Pan H, Godwin J, Gray R, Arriagada R, Raina V, et al. Long-term effects of continuing adjuvant tamoxifen to 10 years versus stopping at 5 years after diagnosis of oestrogen receptorpositive breast cancer: ATLAS, a randomised trial. Lancet. 2013; 381(9869):805-16. [PubMed: 23219286]

111. Goss PE, Ingle JN, Martino S, Robert NJ, Muss HB, Piccart MJ, et al. Randomized trial of letrozole following tamoxifen as extended adjuvant therapy in receptor-positive breast cancer: updated findings from NCIC CTG MA.17. J Natl Cancer Inst. 2005; 97(17):1262-71. [PubMed: 16145047]

112. Goss PE, Ingle JN, Pritchard KI, Robert NJ, Muss H, Gralow J, et al. Extending AromataseInhibitor Adjuvant Therapy to 10 Years. N Engl J Med. 2016; 375(3):209-19. [PubMed: 27264120]

113. Burstein HJ, Temin S, Anderson H, Buchholz TA, Davidson NE, Gelmon KE, et al. Adjuvant endocrine therapy for women with hormone receptor-positive breast cancer: american society of clinical oncology clinical practice guideline focused update. J Clin Oncol. 2014; 32(21):2255-69. [PubMed: 24868023]

114. Pagani O, Regan MM, Walley BA, Fleming GF, Colleoni M, Lang I, et al. Adjuvant exemestane with ovarian suppression in premenopausal breast cancer. N Engl J Med. 2014; 371(2):107-18. [PubMed: 24881463]

115. Moore HC, Unger JM, Phillips KA, Boyle F, Hitre E, Porter D, et al. Goserelin for ovarian protection during breast-cancer adjuvant chemotherapy. N Engl J Med. 2015; 372(10):923-32. [PubMed: 25738668]

116. Azim HA Jr, Santoro L, Pavlidis N, Gelber S, Kroman N, Azim H, et al. Safety of pregnancy following breast cancer diagnosis: a meta-analysis of 14 studies. Eur J Cancer. 2011; 47(1):7483. [PubMed: 20943370]

117. Margolese RG, Cecchini RS, Julian TB, Ganz PA, Costantino JP, Vallow LA, et al. Anastrozole versus tamoxifen in postmenopausal women with ductal carcinoma in situ undergoing lumpectomy plus radiotherapy (NSABP B-35): a randomised, double-blind, phase 3 clinical trial. Lancet. 2016; 387(10021):849-56. [PubMed: 26686957]

118. Visvanathan K, Hurley P, Bantug E, Brown P, Col NF, Cuzick J, et al. Use of pharmacologic interventions for breast cancer risk reduction: American Society of Clinical Oncology clinical practice guideline. J Clin Oncol. 2013; 31(23):2942-62. [PubMed: 23835710] 
119. Muss HB, Berry DA, Cirrincione CT, Theodoulou M, Mauer AM, Kornblith AB, et al. Adjuvant chemotherapy in older women with early-stage breast cancer. N Engl J Med. 2009; 360(20): 2055-65. [PubMed: 19439741]

120. Emens LA, Davidson NE. The follow-up of breast cancer. Semin Oncol. 2003; 30(3):338-48. [PubMed: 12870135]

121. Kokko R, Holli K, Hakama M. Ca 15-3 in the follow-up of localised breast cancer: a prospective study. Eur J Cancer. 2002; 38(9):1189-93. [PubMed: 12044504]

122. Dal Maso L, Zucchetto A, Talamini R, Serraino D, Stocco CF, Vercelli M, et al. Effect of obesity and other lifestyle factors on mortality in women with breast cancer. Int J Cancer. 2008; 123(9): 2188-94. [PubMed: 18711698]

123. Ballard-Barbash R, Friedenreich CM, Courneya KS, Siddiqi SM, McTiernan A, Alfano CM. Physical activity, biomarkers, and disease outcomes in cancer survivors: a systematic review. J Natl Cancer Inst. 2012; 104(11):815-40. [PubMed: 22570317]

124. Betof AS, Dewhirst MW, Jones LW. Effects and potential mechanisms of exercise training on cancer progression: a translational perspective. Brain Behav Immun. 2013; 30(Suppl):S75-87. [PubMed: 22610066] 


\section{Key Points}

- $\quad$ Breast-conserving therapy and mastectomy are well-established local therapies for early-stage invasive breast cancer, and have equivalent survival and recurrence outcomes with multimodal therapy.

- Neoadjuvant chemotherapy is increasingly used to downstage disease in the breast and axilla, allowing breast conservation and avoiding axillary lymph node dissection, and is most likely to be successful in a unicentric, HER2 positive or triple negative breast cancer.

- $\quad$ Adjuvant medical therapies are given after breast surgery to eradicate clinically and radiographically occult micrometastatic disease that may develop into frank metastases if untreated.

- Disease burden and biology determine the patient's risk of recurrence, which guides the selection of appropriate adjuvant medical therapies. 


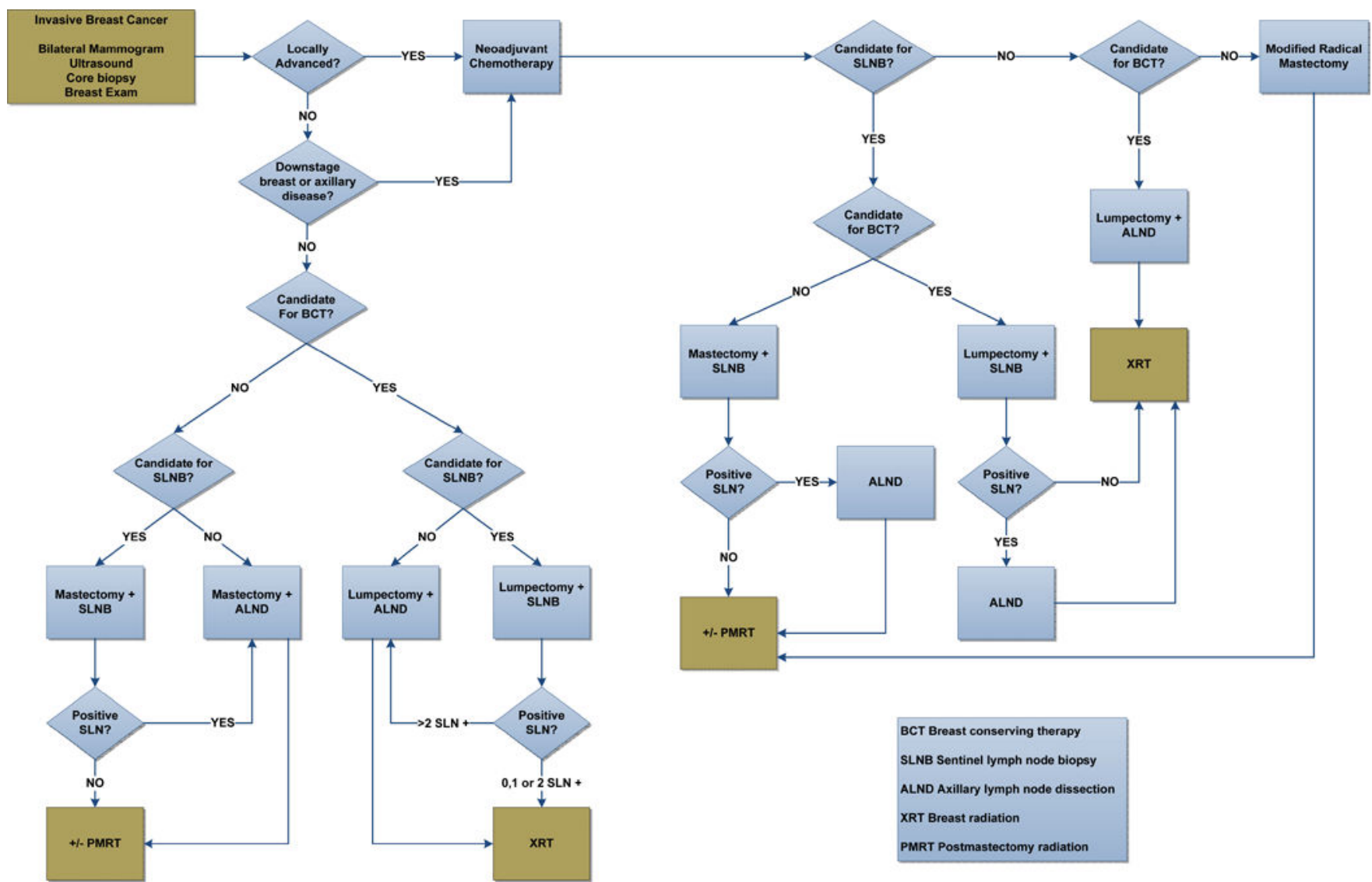

Figure 1. Invasive breast cancer: Algorithm for local therapy

SLNB, sentinel lymph node biopsy; BCT, breast-conserving therapy; ALND, axillary lymph node dissection; XRT, breast radiation; SLN, sentinel lymph node; PMRT, postmastectomy radiation therapy 
Node-negative, hormone receptor-positive and HER2-negative breast cancer

$\mathrm{RS}<11$
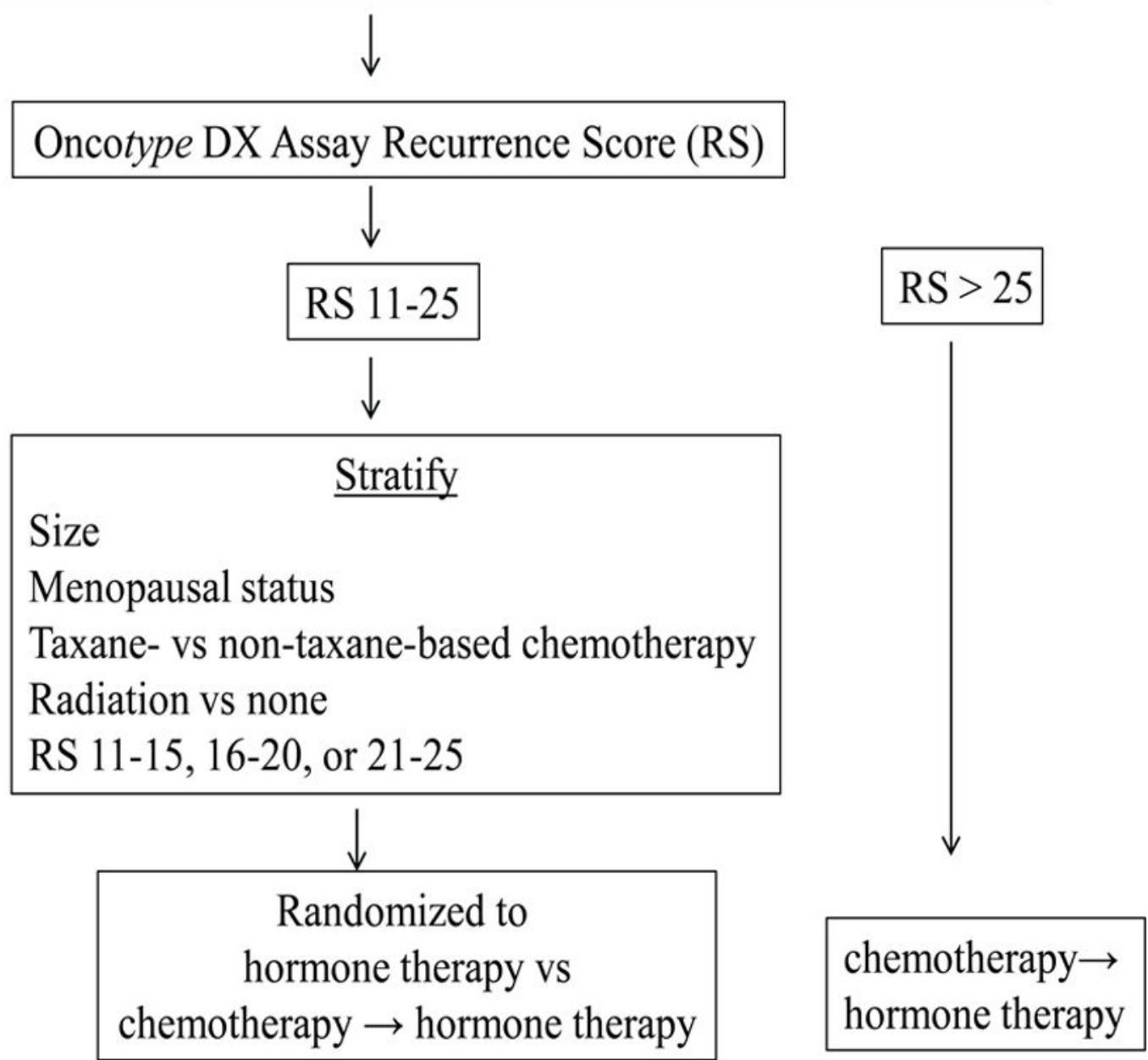

Figure 2. TAILORx for node-negative, hormone receptor-positive and HER2-negative breast cancer

RS: recurrence score 


\section{RxPONDER}

Node-positive (1-3 nodes), hormone receptor-positive and HER2-negative breast cancer

Oncotype DX Assay Recurrence Score (RS)

$\downarrow$

$\mathrm{RS} \leq 25$

$\mathrm{RS}>25$

$\downarrow$

\section{$\underline{\text { Stratify }}$}

Menopausal status

Axillary dissection vs sentinel node biopsy

RS $0-13$ or $14-25$

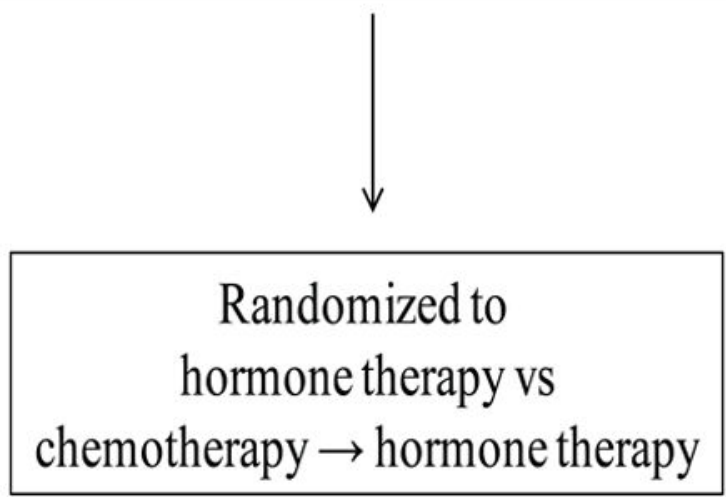

Figure 3. RxPONDER for node-positive, hormone receptor-positive and HER2-negative breast cancer

RS: recurrence score 


\section{Table 1}

False-negative rate of sentinel lymph node biopsy following neoadjuvant chemotherapy in clinically nodepositive breast cancer

\begin{tabular}{|l|c|c|c|}
\hline & \multicolumn{3}{|c|}{ False-Negative Rate (\%) } \\
\hline Trial & Overall & Radioactive isotope and blue dye & $\geq 3$ sentinel nodes removed \\
\hline $\begin{array}{l}\text { ACOSOG Z1071 } \\
(\mathbf{n}=\mathbf{6 4 9})\end{array}$ & 12.6 & 10.8 & 9.1 \\
\hline $\begin{array}{l}\text { SENTINA } \\
(\mathbf{n}=\mathbf{6 4 2})\end{array}$ & 14.2 & 8.6 & 7.3 \\
\hline $\begin{array}{l}\text { SN FNAC } \\
(\mathbf{n}=\mathbf{1 5 3})\end{array}$ & 13.3 & 5.2 & $4.9^{*}$ \\
\hline
\end{tabular}

*epresents false-negative rate with $>2$ sentinel lymph nodes removed

ACOSOG, American College of Surgeons Oncology Group; SN FNAC, Sentinel Node Biopsy Following Neoadjuvant Chemotherapy 